\title{
Electrochemical determination of minocycline in pharmaceutical preparations
}

\author{
I.G. Tanase ${ }^{1}$, I.G. David ${ }^{1}$, G.L. Radu ${ }^{2, *}$, E.E. Iorgulescu ${ }^{1}$ and S. Litescu ${ }^{2}$ \\ ${ }^{1}$ Department of Analytical Chemistry, Faculty of Chemistry, University of Bucharest, \\ 13, Blvd. Republicii, Bucharest, Romania \\ ${ }^{2}$ Department of Analytical Biochemistry, National Institute for Biological Sciences, \\ 296, Spl. Independentei, P.O. Box 17-16, 77748 Bucharest, Romania
}

\begin{abstract}
The possibility of electrochemical determination of minocycline on mercury and solid electrodes by various voltammetric and polarographic techniques has been undertaken. The influence of some chemical (ionic strength and $\mathrm{pH}$ ) and instrumental parameters on the main reduction signal of minocycline was investigated. The alternating current polarographic (ACP) technique was applied to the minocycline determination either in pure form or in a commercial pharmaceutical preparation. The common excipients did not interfere. The antibiotic could be detected in the concentration range $110^{-3}-510^{-6} \mathrm{~mol} \mathrm{~L}^{-1}$. The detection limit for the quantitative determination by ACP was $110^{-6} \mathrm{~mol} \mathrm{~L}^{-1}$ minocycline in aqueous medium of $0.1 \mathrm{M} \mathrm{NaCl}$. The mean recovery was $99.2 \%$ with a relative standard deviation $(\mathrm{RSD})$ of $2.93 \%(n=8)$.
\end{abstract}

\section{Introduction}

Minocycline is the commercial name of the semisynthetic compound 7-dimethylamino-6-dimethyl-desoxytetracycline hydrochloride, that is a yellow crystalline, slightly hygroscopic, photo-sensitive powder. It belongs to the first group of semisynthetic tetracyclines beside doxycycline and methacycline. Its chemical structure (I) includes a second dimethylamino group. Minocycline has a major therapeutic interest, being active against staphylococci resistant to other tetracyclines. Today, an accessible semisynthetic method is used for its preparation, starting from 6-dimethyl-desoxytetracycline [1].<smiles>CN(C)c1ccc(O)c2c1CC1CC3[C@@H](N(C)C)C(O)(O)C(C(N)=O)C(=O)[C@]3(C2=O)C(O)=C1O</smiles>

Analytical techniques employed for minocycline determination include chromatography [2-5], molecular absorption spectrometry [6-8], electrophoresis [9] and differential pulse polarography $[10,11]$.

This paper discusses the possibility of using polarographic and voltammetric techniques for minocycline analysis as simple and accurate methods for its determination from dosage forms. The procedure involving, usually, a simple dilution because the most excipients did not interfere in the subsequent determination steps $[12,13]$.

Due to the presence, in the molecular structure, of the possible reducible carbonyl groups, like in other previously investigated tetracyclines [14-17], the polarographic and voltammetric behaviour of this compound was tackled employing cyclic (CV), linear sweep (LSV), differential pulse (DPV) and square wave voltammetry (SWV) and sinusoidal alternating current polarography (ACP). The possibility of quantitative determination of minocycline was established using LSV, SWV, DPV and ACP.

\section{Experimental}

\section{Apparatus}

The voltammetric measurements were carried out using a Galvanostat/Potentiostat system Model 273 A with a multifunctional mercury electrode 303 A (EG \& G Princeton Applied Research) and a $\mathrm{Ag} / \mathrm{AgCl}$ reference electrode.

ACP with sensitive phase measurements were performed with a polarographic instrument PRG 3 (Solea-Tacussel), with three electrodes. A dropping mercury electrode with the following characteristics: glass capillary type CMT 10/68 Tacussel with the inner diameter $60-80 \mu \mathrm{m}, q=5.53 \mathrm{mg}$ $\mathrm{s}^{-1}, \tau=2.08 \mathrm{~s}$, was used as working electrode at $E=-1.00$ $\mathrm{V}$ vs. SCE in $1.00 \mathrm{M} \mathrm{NaOH}$, at a mercury column height of $h=65 \mathrm{~cm}$. A K401 Radiometer calomel electrode and a Pt 121 coiled electrode (Solea-Tacussel) with a great active area were used as reference and auxiliary electrode, respectively.

A thermostated polarographic cell was used to do all measurements at controlled temperature $\left(25.0 \pm 0.1{ }^{\circ} \mathrm{C}\right)$. The dissolved oxygen from the polarographically analysed solutions was eliminated by bubbling a pure argon stream.

\section{Reagents}

All used substances were of analytical or pharmaceutical grade. The water used for the vessel cleaning and for solution preparation was tridistilled. 


\section{Results and discussions}

The elaboration of a quantitative polarographic and voltammetric determination method of a chemical compound needs, first of all, a rigorous study of the reduction or oxidation properties of the species at the chosen working electrode in different supporting electrolytes. Thus, minocycline electroactivity was first investigated by $\mathrm{CV}$ at a solid glassy carbon electrode (GCE) - figure 1A and a hanging mercury drop electrode (HMDE) - figure 1B.

The cyclic voltammogram obtained at the HMDE shows two reduction peaks at waves during the direct scan, anodiccathodic and a well-defined oxidation peak at the inverse scan: cathodic-anodic, whereas the cyclic voltammogram obtained at the GCE presents only one reduction and one oxidation peak at the direct and inverse scan, respectively. Cyclic voltammograms demonstrated that minocycline is electroactive at both mercury and solid working electrodes. In both cases, the form of the cyclic voltammogram and the heights of maximum peak currents are dependent on the scan rate, optimum values being among $200-600 \mathrm{mV} \mathrm{s}^{-1}$. Differences between the potential of the cathodic reduction peak $E_{\mathrm{pc}}$ and that of the anodic oxidation peak $E_{\mathrm{pa}}$ were $\Delta E_{\mathrm{Hg}}=135 \mathrm{mV}$ at the $\mathrm{HMDE}$ (considering the reduction peak with $E_{\mathrm{pc}}=-0.850 \mathrm{~V}$ ) and $\Delta E_{\mathrm{GC}}=137 \mathrm{mV}$ at the GCE. Though the two differences $\Delta E_{\mathrm{p}}$ have close values, both are different from the values corresponding to reversible electrode processes $(0.059 / z \mathrm{~V})$, indicating that the reversibility of these processes is low.

The minocycline electroactivity and the possibilities of its quantitative determination were also investigated by LSV, SWV and DPV. All these voltammetric techniques demonstrated the minocycline reducibility at a mercury electrode. The reduction process gives a main reduction peak at potentials among -0.800 and $-1.200 \mathrm{~V}$ vs. $\mathrm{Ag} / \mathrm{AgCl}$ and also some other peaks in the range $-0.350-0.450$ and/or -1.200 $-1.400 \mathrm{~V}$ vs. $\mathrm{Ag} / \mathrm{AgCl}$. By applying these three techniques the main signal was well defined and sensitive to the variation of the experimental parameters further presented.

Subsequently minocycline reduction was also studied at the DME in aqueous acid, neutral and alkaline media, using phase sensitive ACP. The sinusoidal alternating current polarogram of minocycline presents more peaks, their number and shape being influenced by the chemical parameters of the system in which the reduction process occurs (ionic strength, nature and concentration of supporting electrolyte, $\mathrm{pH})$. Due to these reasons ACP was used to evidence the shape modifications of the current-potential curves during the variation of those parameters or of the instrumental parameters. Thus, to evaluate the ionic strength and the $\mathrm{pH}$ influence on the polarograms, aqueous $\mathrm{NaOH}$ and $\mathrm{NaCl}$ solutions of various concentrations and Britton-Robinson buffers, respectively, were used.

The sinusoidal alternating current polarograms obtained for minocycline reduction in solutions of different $\mathrm{NaCl}$ concentrations (see Fig. 2) indicated that the ionic strength influences the polarogram shape, the peaks number and the maximum peak currents. Thus, depending on the ionic strength, the polarograms showed 3 or 4 peaks: one very tight and sensitive to ionic strength at cathodic potentials among -0.400 and $-0.600 \mathrm{~V}$, a larger one (at high ionic strength) or two peaks (at low ionic strength) in the range -

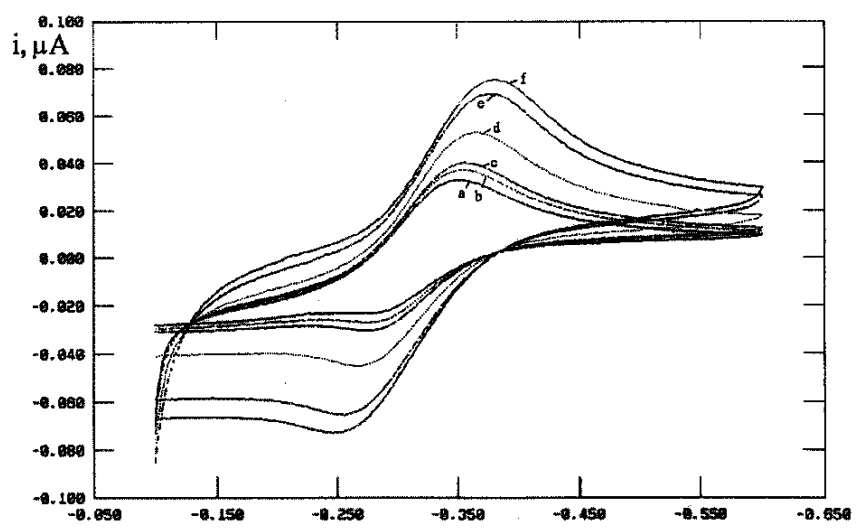

A

E, $\mathrm{V}$ vs. $\mathrm{Ag} / \mathrm{AgCl}$

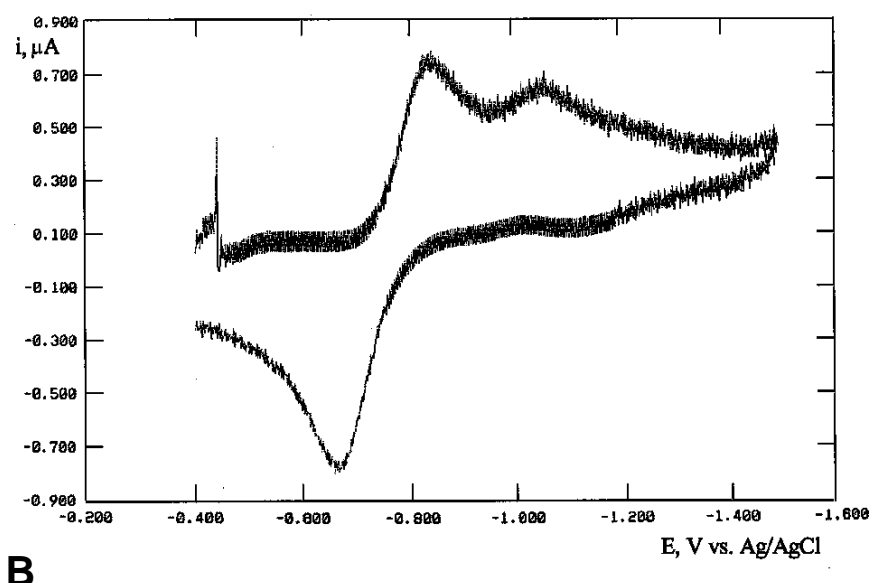

B

Fig. 1. Anodic - cathodic cyclic voltammograms of minocycline $\left(C=210^{-4} \mathrm{~mol} \mathrm{~L}^{-1}\right)$ in $0.1 \mathrm{M} \mathrm{NaCl}$ at A) GCE: a) $60 \mathrm{mV} \mathrm{s}^{-1}$, b) $80 \mathrm{mV} \mathrm{s}^{-1}$, c) $100 \mathrm{mV} \mathrm{s}^{-1}$, d) $200 \mathrm{mV} \mathrm{s}$, e) $400 \mathrm{mV} \mathrm{s}^{-1}$, f) $500 \mathrm{mV} \mathrm{s}^{-1}$ and B) HMDE, $v=200 \mathrm{mVs}^{-1}$.

0.900 to $-1.300 \mathrm{~V}$ and a strongly distorted peak, situated at potentials from -1.600 to $-1.800 \mathrm{~V}$ vs. SCE.

The $\mathrm{pH}$ influence on the shape of the minocycline alternating current polarograms proved that only two peaks appear in weak acidic media at potentials among -1.100 and $-1.400 \mathrm{~V}$ vs. SCE. In alkaline buffers, as in $\mathrm{NaOH}$ solutions, three or even four peaks were registered in the same potential range.

Comparing the sinusoidal alternating current polarograms with the cyclic voltammograms obtained for minocycline at the HMDE and at GCE (Fig. 1), it can be observed that the reduction process is complicated by other physico-chemical phenomena (adsorption) which are taking place at the electrode-solution. However, in $0.1 \mathrm{M} \mathrm{NaCl}$ solution the signal corresponding to the minocycline reduction is in the range -0.800 to $-1.100 \mathrm{~V}$ vs. SCE both in CV and ACP (signals were strongly distorted by the ionic strength and the $\mathrm{pH}$ variation).

Subsequently, the influence of the characteristic instrumental parameters (the amplitude and the frequency of the superimposed alternating signal, the scan rate, the angle of 


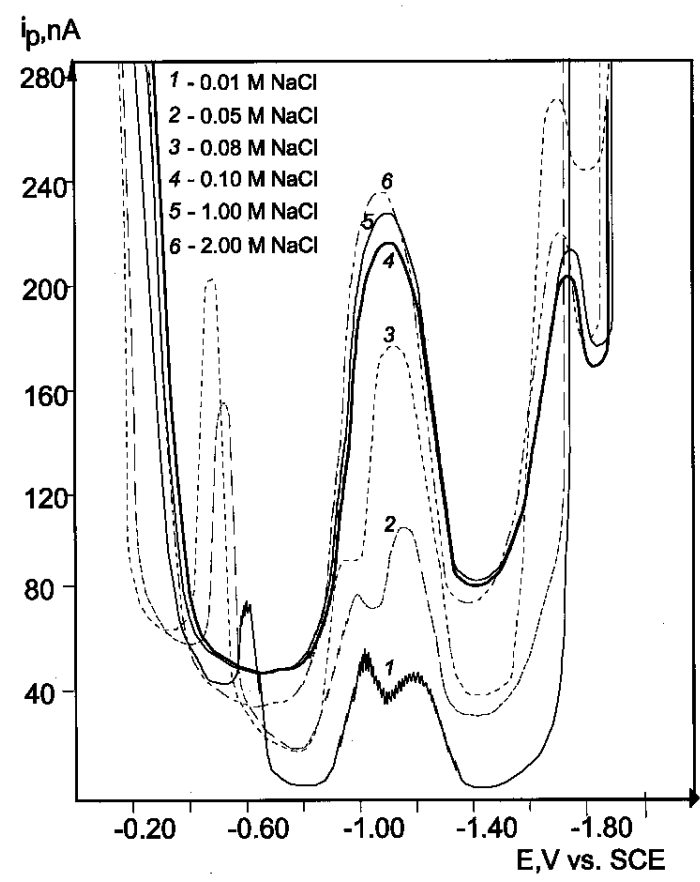

Fig. 2. The influence of ionic strength on the minocycline reduction using ACP in NaCl. $C=210^{-4} \mathrm{~mol} \mathrm{~L}^{-1}$ minocycline; $v=$ $80 \mathrm{~Hz} ; \Delta E=10 \mathrm{mV} ; \varphi=0^{\circ}$.

Table I. The influence of the amplitude and frequency of the superimposed alternating voltage on the maximum peak current in ACP reduction of minocycline; $C=410^{-4} \mathrm{~mol} \mathrm{~L}^{-1} ; 0.1 \mathrm{M} \mathrm{NaCl} ; \varphi=$ $0^{\circ}$.

\begin{tabular}{lcc}
\hline$\Delta E(m V)$ & $v(H z)$ & $i_{p}(n A)$ \\
\hline 2 & & 125 \\
4 & 80 & 185 \\
6 & & 240 \\
8 & 36 & 310 \\
10 & 36 & \\
10 & 96 & \\
40 & 65 & 245 \\
10 & 350 & \\
80 & 555 & \\
100 & 600 & \\
140 & & \\
\hline
\end{tabular}

the detection phase) on the obtained signals was checked up and optimised. Some results using ACP are listed in table I. The dependence of the maximum peak currents on the magnitude of the tested parameters is obvious.

Further, the influence of minocycline concentration on the maximum peak current intensities in ACP was investigated in $0.1 \mathrm{M} \mathrm{NaCl}$ medium in the range $210^{-5}-410^{-4} \mathrm{~mol} \mathrm{~L}^{-1}$ (see Fig. 3). The calibration graph at different amplitudes of the superimposed alternating potential (see the equations presented in Tab. II) proved an increased sensitivity of the minocycline determination at high amplitudes of the alternative superimposed signal.

The ACP technique was applied for the minocycline determination either in pure form or in a commercial phar-

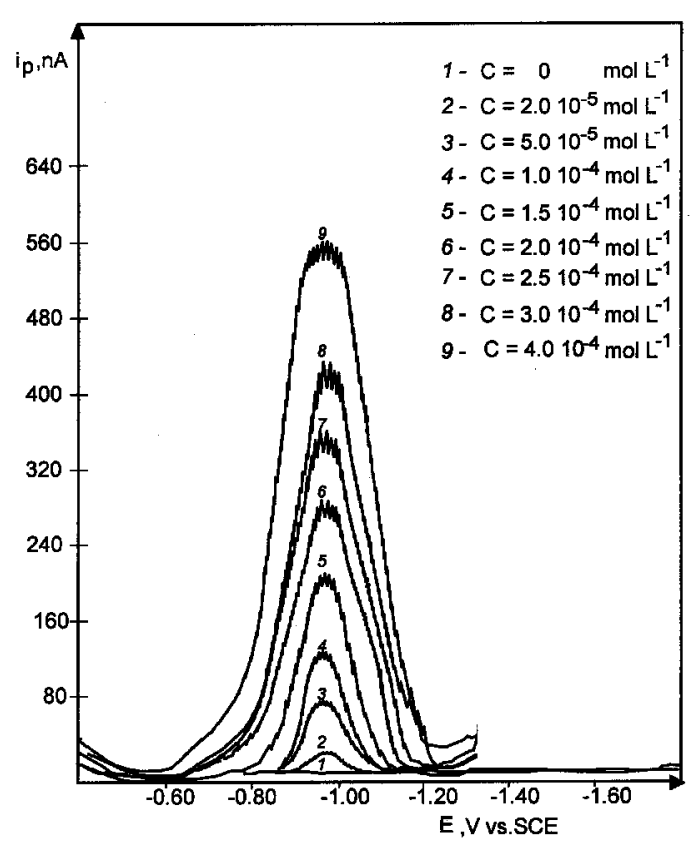

Fig. 3. Sinusoidal alternating current polarograms for minocycline determination in $0.1 \mathrm{M} \mathrm{NaCl}$ the concentration range $210^{-5}-4$ $10^{-4} \mathrm{~mol} \mathrm{~L}^{-1}, v=100 \mathrm{~Hz} ; \Delta E=10 \mathrm{mV} ; \varphi=0^{\circ}$.

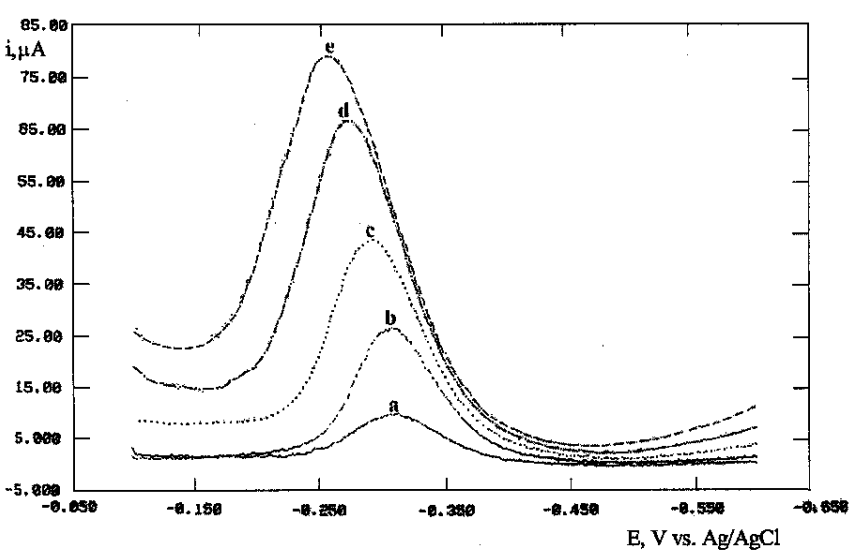

Fig. 4. The influence of the pulse height on the maximum peak current $\left(i_{\mathrm{p}}\right)$ for the minocycline reduction in $0.1 \mathrm{M} \mathrm{NaCl}$ by DPV on $\operatorname{GCE}\left(C=210^{-4} \mathrm{~mol} \mathrm{~L}^{-1}\right.$ minocycline $)$; a) $\Delta E=10 \mathrm{mV}$, b) $25 \mathrm{mV}$, c) $50 \mathrm{mV}$, d) $75 \mathrm{mV}$, e) $100 \mathrm{mV}$.

maceutical preparation (Mestacine tablets). The common excipients did not interfere. The mean recovery was $99.2 \%$ with a $\mathrm{RSD}=2.93 \%$ for $n=8$.

After the establishing of the optimal experimental conditions (chemical and instrumental parameters), figure 4, minocycline was also determined on GCE using DPV.

The possibility of minocycline determination at lower concentration levels was investigated by adsorptive stripping voltammetry at the HMDE in aqueous $0.1 \mathrm{M} \mathrm{NaCl}$ solutions. The obtained voltammograms presented two peaks $\left(E_{\mathrm{p} 1}=\right.$ $-0.340 \mathrm{~V}$ and $E_{\mathrm{p} 2}=0.550 \mathrm{~V}$ vs. $\left.\mathrm{Ag} / \mathrm{AgCl}\right)$, but only the first 


\section{Original articles}

Table II. Performances of quantitative minocycline determination employing different electrochemical techniques.

\begin{tabular}{|c|c|c|c|c|c|c|}
\hline $\begin{array}{l}\text { Electrochemical } \\
\text { technique }\end{array}$ & Optimum parameters & $\begin{array}{l}\text { Linear range } \\
\quad\left(\mathrm{mol} \mathrm{L} \mathrm{L}^{-1}\right)\end{array}$ & $\begin{array}{l}\text { Equation of the } \\
\text { calibration graph }\end{array}$ & $\begin{array}{l}\text { Detection limit } \\
\quad\left(\text { mol L }^{-1}\right)\end{array}$ & $\begin{array}{l}\text { Sensitivity } \\
(\mu A \mathrm{~L} / \mathrm{mol})\end{array}$ & $\begin{array}{l}\text { Correlation } \\
\text { coefficient }\end{array}$ \\
\hline $\mathrm{ACP}$ & $\begin{array}{l}\Delta E=5 \mathrm{mV} ; v=100 \mathrm{~Hz} ; \varphi=0^{\circ} \\
\Delta E=10 \mathrm{mV} ; v=100 \mathrm{~Hz} ; \varphi=0^{\circ} \\
\Delta E=15 \mathrm{mV} ; v=100 \mathrm{~Hz} ; \varphi=0^{\circ}\end{array}$ & $110^{-3}-510^{-6}$ & $\begin{array}{c}i_{\mathrm{p}}=-0.0015+751 \mathrm{C} \\
i_{\mathrm{p}}=0.00085+1400 \mathrm{C} \\
i_{\mathrm{p}}=0.0043+2097 \mathrm{C}\end{array}$ & $110^{-6}$ & $\begin{array}{c}750.99 \\
1400.00 \\
2097.00\end{array}$ & $\begin{array}{c}0.992 \\
0.99992 \\
0.99995\end{array}$ \\
\hline LSV at HMDE & $v=400 \mathrm{mV} \mathrm{s}^{-1}$ & $110^{-3}-110^{-5}$ & $i_{\mathrm{p}}=0.0039+678.97 \mathrm{C}$ & $810^{-6}$ & 678.96 & 0.9997 \\
\hline DPV at HMDE & $\Delta E=25 \mathrm{mV} ; v=200 \mathrm{mV} \mathrm{s}^{-1}$ & $110^{-3}-110^{-6}$ & $i_{\mathrm{p}}=2.37+48967 \mathrm{C}$ & $510^{-7}$ & 48969.37 & 0.985 \\
\hline DPV at GCE & $\Delta E=50-100 \mathrm{mV} ; v=200 \mathrm{mV} \mathrm{s}^{-1}$ & $110^{-3}-110^{-5}$ & $i_{\mathrm{p}}=0.39+918.2 \mathrm{C}$ & $7.510^{-6}$ & 918.59 & 0.994 \\
\hline SWV at HMDE & $\begin{array}{c}\Delta E=25 \mathrm{mV} ; v=150 \mathrm{~Hz} \\
v=200 \mathrm{mV} \mathrm{s}^{-1}\end{array}$ & $110^{-3}-110^{-6}$ & $i_{\mathrm{p}}=3.7+38249 \mathrm{C}$ & $510^{-7}$ & 38252.7 & 0.990 \\
\hline AdSV & $\begin{array}{c}E_{\mathrm{acc}}=-0.950 \mathrm{~V} \text { vs. } \mathrm{Ag} / \mathrm{AgCl} \\
t_{\mathrm{acc}}=180 \mathrm{~s} ; t_{\mathrm{eq}}=30 \mathrm{~s} \\
v=200 \mathrm{mV} \mathrm{s}^{-1}\end{array}$ & $110^{-6}-510^{-8}$ & $i_{\mathrm{p}}=-21-23897713 \mathrm{C}$ & $110^{-9}$ & -23897734 & 0.996 \\
\hline
\end{tabular}

one responded to the variation of minocycline concentration. In order to optimise the determination, the influence of some parameters (accumulation potential and time, anodic scan rate) on the current intensities of the two minocycline stripping peaks was studied (Fig. 5). At the established optimum conditions $\left(E_{\text {acc }}=-0.95 \mathrm{~V}\right.$ vs. $\mathrm{Ag} / \mathrm{AgCl}, t_{\text {acc }}=180 \mathrm{~s}, t_{\text {eq. }}=$ $30 \mathrm{~s}$ and $\left.v=100 \mathrm{mV} \mathrm{s}^{-1}\right)$ the current intensity of the first peak responded linearly to minocycline concentration in the range $110^{-6}-510^{-8} \mathrm{~mol} \mathrm{~L}{ }^{-1}$, according to the equation presented in table II.

The mean results of the quantitative minocycline determination by different electrochemical techniques are summarized and presented in table II.

\section{Conclusions}

Minocycline is polarographically and voltammetrically reducible at mercury (DME, HMDE) and solid (GCE) electrodes, presenting well-defined response signals in CV, LSV, SWV, DPV and AdSV at mercury electrodes and in DPV at GCE.

The ACP reduction curves are complex, the number and shape of the peaks depending on both the chemical parameters of the system and on the characteristic parameters of the employed technique.

ACP was used for the minocycline determination from dosage forms, this electrochemical method was rapid and did not need any sample pre-treatment other than the drug dissolution. The method enables the estimation of the drug concentration without interferences from the excipients contained in the formulation.

\section{References}

1. Zotta, V. Chimie Farmaceutica, Medicala (ed.), Bucuresti, 1985; p. 135.

2. Bryan, P. D.; Stewart, J. T. J. Pharm. Biomed. Anal. 1994, 12, 675-692.

3. Naidong, W.; Vermeulen, K.; Quintens, I.; Roets, E.; Hoogmartens, J.; Chromatographia 1992, 33, 560-566.

4. Weng, N. D.; Thuranira, J.; Vermeulen, K.; Roets, E.; Hoogmartens, J. J. Liq. Chromatogr. 1992, 15, 2529-2545.

5. Boecker, R. H.; Peter, R.; Machbert, G.; Bauer, W. J. Chromatogr. Biomed. Appl. 1991, 106, 363-374.

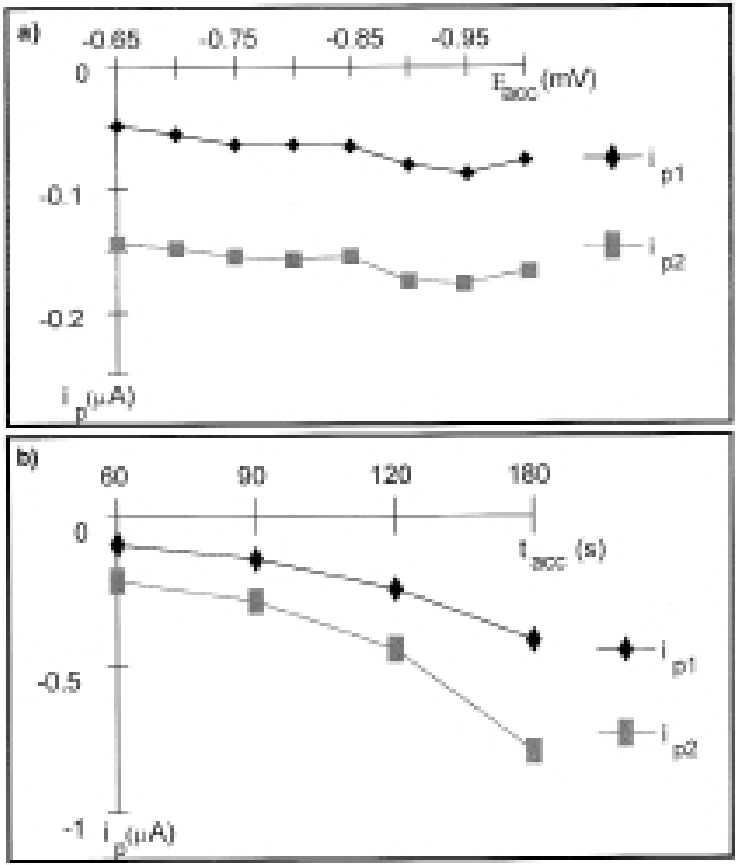

Fig. 5. The maximal peak currents variation in AdSV determination of minocycline. $\left(C=110^{-6} \mathrm{~mol} \mathrm{~L}^{-1}\right)$ with: a) accumulation potential $E_{\text {acc }}, t_{\text {acc }}=180 \mathrm{~s}, t_{\text {eq }}=30 \mathrm{~s}, v=100 \mathrm{mV} \mathrm{s}^{-1}$ and b) accumulation time $t_{\text {aac }}, E_{\text {acc }}=-0.950 \mathrm{~V}$ vs. $\mathrm{Ag} / \mathrm{AgCl}, t_{\mathrm{eq}}=30 \mathrm{~s}$, $v=100 \mathrm{mV} \mathrm{s}^{-1}$.

6. Hon, P. K.; Fung, W. K. Analyst 1991, 116, 751-752.

7. Mori, I.; Fujita, Y.; Kawabe, H.; Fujita, K.; Tanaka, T.; Kishimoto, A.; Analyst 1986, 111, 1409-1412.

8. Fujita, Y.; Mori, I.; Kitano, S. Chem. Pharm. Bull. 1983, 3 , 4016-4021.

9. Kondo, F.; Yamaguchi, R. Shokuhin Eiseigaku Zasshi 1988, 29 , 185-191.

10. Cutie, A. J.; Mils, J.; Jochsberger, T. Drug Dev. Ind. Pharm. 1980, $6,77-85$.

11. Jochsberger, T.; Cutie, A. J.; Mills, J. J. Pharm. Sci. 1979, 68, 1061-1079.

12. Ivaska, A.; Smyth, W. F. Electroanalysis in Hygiene, Environmental, Clinical and Pharmaceutical Chemistry, Elsevier, Amsterdam, 1980 
13. Kissinger, P. T.; Heineman, W. R. Laboratory Techniques in Electroanalytical Chemistry, Marcel Dekker, New York, 1980.

14. Selgerman, H. Electroanalytical Chemistry, Vol. 11, Marcel Dekker, New York, 1979.

15. Bersier, P. M.; Bersier, J. in: Wilson and Wilson's Comprehensive Analytical Chemistry, Smith, M. R.; Vas, J. Eds., Vol. 27, Elsevier, Amsterdam, 1992.
16. Bersier, P. M.; Bersier, J. Electroanalysis 1994, 6, 171-191.

17. Tanase, I.; David, I. G.; Radu, G. L.; Iorgulescu, E. E. Analusis 1996, 24, 281-284. 